\title{
A PERCEPÇÃO DOS BOLSISTAS DO PROJETO DE EXTENSÃO “A INSERÇÃO DA UNIVERSIDADE NO FUTEBOL" A RESPEITO DA RELAÇÃO TEORIA E PRÁTICA
}

\section{THE PERCEPTION OF THE SCHOLARSHIP STUDENTS OF THE EXTENSION PROJECT “THE INSERTION OF THE UNIVERSITY IN SOCCER" REGARDING THE RELATIONSHIP BETWEEN THEORY AND PRACTICE}

\author{
Otávio Nogueira Balzano $^{1}$ (D), Abraham Lincoln De Paula Rodrigues $^{1 *}$ (D) Gilberto Ferreira da Silva $^{2}$ (D) \\ , Leandro Veras Castelo Branco ${ }^{1}$ iD
}

${ }^{1}$ Universidade Federal do Ceará, Fortaleza, CE, Brasil.

${ }^{2}$ Universidade La Salle, Canoas, RS, Brasil.

*lincoln7777@hotmail.com

\section{RESUMO}

Na Educação Física há uma discussão sobre a dicotomia teoria e prática, e quanto uma dá subsídios para a outra obter legitimidade. Isso leva a pensar sobre a formação de novos profissionais na área. No ambiente de formação, há disciplinas teóricas que parecem estar longe da realidade externa à universidade. Isso faz com que haja uma distorção da situação real de ensino. O objetivo do estudo foi verificar a percepção dos bolsistas sobre o projeto de extensão "A inserção da Universidade no Futebol” em relação à dimensão teoria e prática na formação em Educação Física. Foi uma pesquisa descritiva exploratória, e com abordagem qualitativa, cuja amostra foi composta por 5 bolsistas do projeto de extensão referido. Os dados foram produzidos através de um questionário aberto, aplicado aos bolsistas e analisados juntamente com o referencial teórico em busca dos resultados. A análise dos dados aponta para a manutenção da tensão entre teoria e prática, onde o primeiro concentra-se na configuração de um arcabouço conceitual distanciado da prática concebida como limitada a uma "experiência de si" durante a ação educativa. Por outro lado, as práticas extensionistas permitiram ampliar o conhecimento da realidade profissional e, paradoxalmente, o exercício de aplicação das teorias apreendidas no ambiente acadêmico.

Palavras-chave: Educação Física. Extensão universitária. Formação. Futebol.

\section{ABSTRACT}

In Physical Education, there is a discussion about the theory and practice dichotomy, and how much one provides support to the other to obtain legitimacy. This leads to thinking about the training of the new professionals in the area. In the training environment, there are theoretical subjects, which seem to be far from a reality outside of the university. This causes a misinterpretation of the real situation of education. The aim of this study was to verify the perception of the scholarship students about the extension Project "The insertion of the university in soccer" regarding the dimension theory and practice in the Physical Education training. It was conducted qualitative research, with a qualitative approach, and composed of five scholarship students from the extension project. The data were collected through an open questionnaire, applied to the students, and analyzed with the theoretical framework searching for the results. The data analysis indicates the tension maintenance between theory and practice, which the first one concentrates on the setting of a conceptual framework far from the practice conceived as a limited "experience of yourself" during an educational activity. However, the extensionists practices allowed to widen the knowledge of the professional expertise and, paradoxically, the application of the theories learned in the academic environment. Keywords: Physical Education. University Extension. Theory and Practice. Soccer. 


\section{INTRODUÇÃO}

Na área da Educação Física (EF), há uma forte discussão sobre a dicotomia teoria e prática e quanto uma fornece subsídios para a outra obter legitimidade. Isso nos leva a pensar sobre a própria formação de novos profissionais de EF. O presente estudo nos leva a pensar sobre a própria formação de novos profissionais de EF traz à tona alguns questionamentos: Que profissionais estão sendo formados? Como eles estão sendo formados? Que conhecimentos/experiências norteiam a formação desses novos profissionais?

Para Darido (1995), a dicotomia entre teoria e prática se deve em razão do paradigma positivista presente na produção de conhecimento. No qual essa produção visa a atender a lógica positivista, pouco auxiliando a prática pedagógica dos profissionais de EF, justamente por apresentar uma linguagem diferenciada da usada pelo professor no seu dia a dia. Assim, há por parte do professor uma construção do conhecimento útil por meio do conhecimento tácito que gera uma prática construída e estruturada socialmente.

Nota-se que não é aconselhável encarar esses dois aspectos como sequenciais e, portanto, não se deve tentar definir quem vem primeiro. Visto que ambos caminham lado a lado, afirmação que pode ser confirmada tanto na prática pedagógica quanto na teorização dos conteúdos. Para que haja a prática em si, o professor deve apresentar conhecimentos teóricos ainda que básicos sobre tal assunto, assim como para teorizar algo é necessário que ocorra uma experimentação, assim os conceitos são validados pela prática.

Strelhow (2007) ratifica a afirmação acima e classifica a relação teoria e prática como uma relação dinâmico-dialógica, na qual as duas estão ligadas, já que há reflexos de uma na outra. Conforme Darido (1995), existem algumas características próprias do modelo positivista que distanciam a teoria da prática e acabam por inviabilizar ou atrapalhar o emprego dos conhecimentos científicos na prática profissional, dentre elas: pesquisas realizadas em situações artificiais, geralmente em situação de laboratório, emprego de tarefas distantes do contexto real, busca de uma fundamentação teórica generalizadora, o negligenciamento do contexto de trabalho do profissional e a fragmentação do conhecimento. Essas características são responsáveis por impedir que conhecimentos produzidos possam ser organizados de maneira a auxiliar a prática pedagógica em EF.

Ainda, Darido (1995) complementa que esse distanciamento entre teoria e prática ocorre pelo fato de o professor possuir uma linguagem não formalizada e sustentada no conhecimento tácito, contrária à linguagem utilizada pelos pesquisadores que acatam as exigências da ciência positivista.

Na mesma linha, Gunther e Molina Neto (2000) garantem que irá existir essa separação entre teoria e prática enquanto permanecer o atual distanciamento entre produção acadêmica e a ação dos professores na escola.

Para Marcelino (1995), muito desse antagonismo que ocasiona a dicotomia entre teoria e prática parte do entendimento do senso comum da sociedade, em que a teoria seria considerada um discurso independente da realidade palpável, enquanto a prática significaria a experiência desvinculada da teoria. Todos esses fatores, juntos com a palavra" Educação Física" intensificam ainda mais essa separação entre os dois termos, visto que a seguinte profissão tem a tendência natural de ser associada a algum tipo de atividade essencialmente prática e separada da teoria, tornando ainda mais distantes os dois conceitos.

No ambiente de formação, há muitas disciplinas teóricas que parecem estar longe da realidade vivenciada no mundo externo à universidade e, quando ocorrem, as práticas são somente entre alunos. Isso faz com que haja uma distorção da situação real de ensino, ocasionando uma falta de contextualização com a realidade e, consequentemente, afetando o desenvolvimento integral do profissional. Com a formação deficitária ocasionada por esses fatores, é possível que os novos profissionais não estejam aptos a enfrentar a concorrência do mercado de trabalho, justamente por esse afastamento da realidade em si. Realidade essa que pode se aproximar dos formandos por meio dos projetos de extensão e dos estágios, os quais visam a proporcionar, também, uma aproximação maior da experiência do discente com a realidade do dia a dia. 
Em relação aos objetivos da extensão, Jezine (2004) considera que a extensão como função acadêmica se confirma pelo estabelecimento da interação ensino-pesquisa, mas também pela construção de um pensamento de sociedade na qual os pilares da formação sejam a crítica e a autonomia. A extensão também deve ensinar mesmo sem ter a função de ensino e, mesmo sem ser pesquisa, deve estimular a busca por soluções dos problemas da sociedade. Na perspectiva do anterior, Melo Neto (2002) descreve que, além de colocar em mútua correlação o ensino e a pesquisa, a extensão assume um papel filosófico de modo que busca a superação da dicotomia entre teoria e prática por meio do encaminhamento das teorias da universidade tratadas no ensino para a prática contextualizada na pesquisa dentro do projeto de extensão.

No aspecto das finalidades da extensão, essa pesquisa abordou o projeto "A inserção da Universidade no Futebol", projeto que se caracterizou por ações processuais contínuas, de caráter educativo, social, cultural, científico, tendo como área principal a educação. O projeto fez-se possível pela Universidade Federal do Ceará (UFC), por meio do Instituto de Educação Física e Esportes (IEFES), sob a coordenação e supervisão do Professor Dr. Otávio Nogueira Balzano, em parceria com a equipe profissional de futebol do Ferroviário Atlético Clube, localizada na Barra do Ceará, no município de Fortaleza e com a colaboração de oito bolsistas remunerados e voluntários.

A escolha da pesquisa na área do futebol justifica-se pelo interesse dos futuros profissionais nessa modalidade. Conforme Drubscky (2003) e Carravetta (2006), existe uma ampla gama de áreas em que o profissional de Educação Física pode inserir-se no cotidiano de um clube. Segundo os autores, é importante que o futuro profissional possua a qualificação necessária para atuar nessa área tão disputada que é o futebol de alto rendimento. Qualificação que vem primeiro pela formação inicial em que são proporcionadas disciplinas que irão embasar a teoria e a prática - entre elas os projetos de extensão, os estágios, as disciplinas práticas - o profissional e depois pela realização de cursos especializantes na área em que se deseja trabalhar.

Nesse âmbito da discussão, é valido debater-se o quanto da teoria encaminha-se para a prática e vice-versa, principalmente no âmbito da Educação Física e no desporto futebol. A partir disso, por meio do estudo, objetivou-se verificar a percepção dos bolsistas sobre o projeto de extensão "A inserção da Universidade no Futebol" em relação à dimensão teoria e prática na formação em Educação Física.

\section{MATERIAL E MÉTODOS}

Trata-se de um estudo de cunho descritivo-exploratório e com uma abordagem predominantemente qualitativa. Para Rodrigues (2007), a pesquisa qualitativa-descritiva objetiva observar, registrar, analisar, classificar, interpretar, descrever e correlacionar os fatos ou ocorrência sem manobrá-los, com o intuito de investigar e descobrir a constância de um fato usando técnicas padronizadas de coleta de dados, como exemplo, questionário e observação sistemática. A pesquisa que foca no estudo exploratório tem por objetivo familiarizar-se e obter uma nova visão do fenômeno, descobrindo ideias novas em relação ao objeto estudado (CERVO; BERVIAN, 1998).

$\mathrm{O}$ estudo foi realizado com os alunos bolsistas (voluntários e remunerados) do projeto de extensão "A inserção da universidade no futebol”, do Instituto de Educação Física e Esportes (IEFES) da Universidade Federal do Ceará (UFC). A amostra foi formada por cinco alunos escolhidos de acordo com os seguintes critérios de inclusão: ser bolsista do projeto a pelo menos seis meses; participar de mais de uma atividade no projeto; ter participado de todas as reuniões pedagógicas do projeto. Visando a preservar o sigilo da identidade dos pesquisados e assim evitar possíveis constrangimentos nas respostas, os participantes foram identificados da seguinte forma: Bolsista 1 (B1), Bolsista 2 (B2), Bolsista 3 (B3), Bolsista 4 (B4) e Bolsista 5 (B5).

Foi confeccionado um questionário aberto com perguntas referentes ao objeto de estudo. No questionário, os bolsistas foram solicitados a expressarem seus conhecimentos sobre questões como: a relação teoria e prática na Educação Física; os projetos de extensão na universidade; a possibilidade de ingressar no mercado de trabalho do futebol; a relevância da prática na formação; a contribuição 
do projeto "a inserção da universidade no futebol" na sua formação; a aproximação do que é ensinado na universidade com a realidade prática. O questionário foi validado por dois profissionais com experiência na área da EF. Para Negrini (2005), os questionários são um dos instrumentos para coleta de dados na pesquisa qualitativa, devendo estar estruturados com uma série de perguntas escritas, elaboradas previamente, com o intuito de averiguar a opinião dos sujeitos aos quais se destinam, sobre algum tema especifico.

Foi feito o contato com os alunos do projeto de extensão e esses preencheram os critérios para integrar a pesquisa, foram convidados a participar da pesquisa, sendo informados sobre os objetivos e o caráter científico da mesma. Após o aceite, os participantes assinaram um termo de consentimento livre e esclarecido (TCLE) e foi marcado um dia de acordo com a disponibilidade de cada pesquisado para aplicação do questionário. A ordem de entrega e de recebimento do instrumento da pesquisa foi totalmente aleatória e teve relação direta com a disponibilidade dos participantes.

As análises dos dados foram constituídas do questionário aplicado com os voluntários do estudo, além do marco teórico da pesquisa. Para o tratamento dos dados, utilizou-se a técnica da análise temática ou categorial, que, segundo Bardin (2002), baseia-se em operações de desmembramento do texto em unidades, ou seja, descobrir os diferentes núcleos de sentido que constituem a comunicação e, posteriormente, realizar o seu reagrupamento em classes ou categorias.

\section{RESULTADOS E DISCUSSÃO}

\section{Teoria e Prática}

Em relação ao conceito de teoria e prática, os participantes direcionaram suas opiniões relatando que teoria está relacionado com ideias, conceitos, observações, algo descritivo. Já a prática está ligada as ações, a participação ativa ao fazer.

"Teoria é um conjunto de ideias, hipóteses e opiniões que procuram explicar determinado tema ou fenômeno de forma ampla e completa. Prática é a aplicação de conhecimentos sobre determinado fenômeno, estando relacionado com o fazer. (B1)

"É o conhecimento puramente racional, conhecimento descritivo. Prática seria a aplicação da teoria, em relação à prática pedagógica é a atividade planejada e colocada em ação". (B2)

"A teoria seria o estudo de determinado assunto de uma forma apenas observacional. Prática é quando, no estudo de determinados assuntos, a participação do indivíduo se dá de forma mais ativa". (B4)

"Teoria: Conceitos, estudos, embasamento adquirido para fundamentar uma prática. Prática: Atividade realizada de forma propriamente dita, que pode ou não ser embasada em alguma teoria". (B5)

Os participantes, no que diz respeito à definição de teoria e prática, estão próximos da definição de Marcelino (1995), quando este descreve que a teoria é um conjunto de conhecimentos sistematizados, empregados na interpretação e esclarecimento de certo problema prático e a prática como o conhecimento obtido por meio da experimentação e de aplicação da teoria. Observa-se que para os colaboradores a prática difere da teoria. Neste sentido, Marcelino (1995) afirma que a teoria seria considerada um discurso independente da realidade palpável, enquanto a prática significaria a experiência desvinculada da teoria. Pode-se considerar que, na opinião dos participantes, existe um distanciamento na relação de teoria e prática.

No que diz respeito à teoria e à prática e o curso de EF na prática pedagógica, os colaboradores colocaram existir muitas vezes um distanciamento da realidade. 
"Há um distanciamento entre a teoria e a prática, pois são poucos os professores que contextualizam a teoria com a prática, apresentando aos alunos teorias que pouco se aplicam na pratica, pois muitas das vezes estas teorias não condizem com a realidade na qual o estudante (futuro professor) estará inserido”. (B1)

"Em boa parte do curso essa relação fica distante, conhecemos bastante a teoria e essa teoria não se aplica a grande parte da nossa atividade”. (B2)

"Dentro de algumas disciplinas é nitido a teoria aliada a prática, mas há alguns erros quanto a disciplinas que deveriam ser mais práticas e acabam sendo completamente teóricas. Quanto a prática pedagógica, se o aluno não se engajar em alguma bolsa ou projeto, essa prática fica restrita a apresentar trabalhos $e$ seminários em sala”. (B4)

Para Darido (1995), o distanciamento entre teoria e prática acontece pelo fato de o professor possuir uma linguagem não formalizada e sustentada no conhecimento tácito, oposta à linguagem usada pelos pesquisadores que acatam as exigências da ciência positivista. Na mesma linha, Gunther e Molina Neto (2000) garantem que existirá essa separação entre teoria e prática enquanto permanecer o atual distanciamento entre a produção acadêmica e a ação dos professores na escola.

Nesse sentido, seria importante uma revisão dos programas das disciplinas e um repensar na atuação pedagógica dos professores. Estes deveriam tentar fazer uma conexão entre teoria e prática, para que os alunos pudessem compreender com mais clareza e objetividade o que está sendo proposto e consiga aplicar em seu futuro profissional. Darido (1995) corrobora essa afirmação quando diz que, apesar da atualização curricular dos cursos de EF, a utilização da teoria na prática permanece sem solução.

Quando perguntados sobre teoria e prática e a EF na Universidade e soluções para superar esse distanciamento entre teoria e prática no curso, os participantes relataram que precisam estudar mais ou se engajar em projetos para vivenciar a realidade, pois existe ainda um distanciamento nas disciplinas. Também relataram que a Universidade precisa abrir mais oportunidades para que aconteçam novas vivências.

"Há um distanciamento entre teoria e prática, pois se percebe que o curso dar muita ênfase as aulas teóricas, e não oportuniza aos alunos as vivencias e intervenções na realidade prática, em variadas áreas de atuação, ficando a cargo do aluno se inserir no mercado de trabalho, através dos projetos de extensão e estágios". (B1)

"Deveria haver mais oportunidades de intervenção prática para os alunos do curso, isso poderia se dar através dos estágios obrigatórios e principalmente através da extensão universitária”. (B1)

"Percebo que tenho que me reciclar todos os dias, ler mais e acho que essa é uma deficiência na maioria dos alunos. Pelo que vi as duas teriam que agir em conjunto, mas nem sempre é assim". (B3)

"Dentro de algumas disciplinas os professores costumam usar a prática aliada a teoria para passar o conhecimento para os alunos, mas isto ocorre em poucas disciplinas. Outras práticas são oferecidas em projetos e bolsas, cabe ao aluno ir atrás de julgar importante para si”. (B4)

"Esse afastamento já devia ter sido ao menos diminuido, com ajuda das disciplinas de prática integrativa, mas o que ocorre é que nessas disciplinas são passados apenas conteúdos teóricos". (B4) 
Darido (1995) concorda que existe esse distanciamento e sugere algumas saídas para diminuir o afastamento entre teoria e prática na formação do professorado de EF, como a realização de aulas práticas desde o início do curso, tentando contextualizá-la por intermédio de um professor que possibilite a reflexão dessa ação.

Marcelino (1995), na mesma linha de pensamento, diz que, para que a formação e a atuação de melhores profissionais possam acontecer, faz-se necessário: estabelecer a especificidade da educação física; conhecer profundamente cada teoria em torno da(s) especificidade(s); haver presença de uma ação profissional embasada e reflexiva que contribua para a produção de novos conhecimentos em torno das especificidades e suas teorias.

A profissão de professor de EF está relacionada muito com a prática, assim, as disciplinas teriam que sempre fazer uma relação com o que os alunos encontrarão fora do ambiente acadêmico. E os alunos também deveriam buscar desde os primeiros momentos no curso, experiências e leituras para sua qualificação.

\section{Extensão Universitária}

No que diz respeito à definição de extensão universitária, os participantes posicionaram suas ideias relacionando o trabalho entre universidade e sociedade, desenvolvendo trabalhos educativos, culturais e científicos e que possibilitem que esses formandos tenham contato com a realidade externa à universidade.

\footnotetext{
"Extensão universitária é um processo de cunho educativo, cultural e científico que procura articular o ensino e a pesquisa, tentando viabilizar a relação entre a universidade e a sociedade". (B1)

"É a ação da universidade junto à comunidade".

"Sim, é ir além da universidade com projetos, pesquisas, cursos etc.".

"A meu ver é uma forma de trazer a prática pedagógica para dentro da formação do aluno, por meio de ações, seja com outros alunos ou pessoas externas à universidade". (B4)
}

"É um trabalho desenvolvido com um público que está fora da universidade".

Melo Neto (2002) trata a extensão como um trabalho social numa conotação objetiva, recomendando que esse seja coparticipado na busca de objetos de pesquisa para a obtenção de novo conhecimento ou reformulação dos já existentes. Para o autor, teríamos uma extensão efetivada na realidade concreta, praticada pela universidade apoiada pela comunidade, se houver a superação da pesquisa e do ensino de forma descontextualizada.

De acordo com as opiniões apresentadas pelos bolsistas pesquisados e relacionando ao que foi citado acima por Melo Neto (2002), teríamos que extensão universitária é o prolongamento da universidade dentro da sociedade. Fator que possibilitaria com que esses alunos participantes de projetos conhecessem a realidade concreta do seu espaço de trabalho, facilitando a contextualização entre as teorias trabalhadas na universidade com a prática no ambiente formal.

Quando perguntados sobre a finalidade da extensão universitária para a sua formação, os participantes colocaram que essa oportunidade possibilitou o conhecimento da realidade profissional, a aplicação da teoria na realidade prática e, também, a importante ligação entre os dois aspectos.

"A extensão universitária veio como uma forma de aplicar os conhecimentos teóricos adquiridos nos bancos acadêmicos na realidade prática, propiciando o conhecimento de uma realidade e uma aprendizagem efetiva, pois houve a ligação entre a teoria e prática". (B1) 
"Proporcionar uma vivência, aplicação na docência e também permite que você erre e conserte antes de entrar no ambiente formal de trabalho". (B2)

"Para mim foi primordial, pois me aproximou de uma área que gosto e abriu minha mente para qual caminho seguir. E, pude ver a realidade como realmente ela é". (B3)

"Muito importante e me proporciona um aprendizado que não teria sem transpor os muros da universidade". (B5)

Segundo Jezine (2004), a extensão como função acadêmica se dá pelo estabelecimento da interação ensino-pesquisa, mas também pela construção de um pensamento de sociedade na qual os pilares da formação sejam a crítica e autonomia. Na mesma linha, Melo Neto (2002) descreve que além de colocar em mútua correlação o ensino e a pesquisa, a extensão assume um papel filosófico de modo que busca a superação da dicotomia entre teoria e prática do encaminhamento das teorias da universidade tratadas no ensino para a prática contextualizada na pesquisa dentro do projeto de extensão.

Como os próprios bolsistas relataram, essa experiência possibilitou o conhecimento da realidade profissional por causa da interação ensino-pesquisa que permitiu a aplicação da teoria na prática pedagógica por meio do projeto de extensão. Isso nos leva ao importante processo e foco central do trabalho, a contextualização da teoria trabalhada na universidade com a prática pedagógica. Para que, com essas intervenções no projeto, os alunos consigam identificar, dentro do fazer pedagógico, uma forma de trabalhar as teorias vistas durante sua formação.

Em relação à contribuição da extensão universitária para o seu desenvolvimento acadêmico, os colaboradores relacionaram o seu desenvolvimento acadêmico no projeto às experiências vivenciadas que possibilitaram um melhor conhecimento e preparação para a prática pedagógica e sua realidade, ocasionando um desenvolvimento profissional e pessoal.

"A extensão universitária propiciou grande desenvolvimento acadêmico, na medida em que foi possível através dos planejamentos feitos para o projeto, grande aprendizagem sobre o futebol, contribuiu também pelo fato de ter sido possivel fazer publicações acadêmicas relatando as experiências vivenciadas, e por ter aberto a possibilidade de realizar a pesquisa de monografia no clube". (B1)

"Fornecendo experiência, conhecimentos que não aprendemos dentro de sala e mostrando uma visão real da prática pedagógica". (B2)

"Com toda certeza, não só acadêmico, mas como pessoa também pude ver a realidade como ela é e criei laços, vi o "valor dos valores", e pude usar toda a experiencia do projeto em outras coisas na bolsa”. (B3)

"Me sinto bem mais preparado quando entro em sala mesmo para apresentar seminários e, tenho certeza que estarei assim quando for ministrar minhas aulas, pois graças à extensão universitária não será mais uma novidade”. (B4)

Para Jezine (2004), a extensão também deve ensinar mesmo sem ter a função de ensino e mesmo sem ser pesquisa deve estimular a busca por soluções dos problemas da sociedade. Relacionando-se o que foi dito pelos participantes com a afirmação da autora, entende-se que a extensão proporciona um desenvolvimento acadêmico de seus participantes justamente por propiciar experiências diferenciadas e inseridas na realidade de trabalho, que por muitas vezes é esquecida dentro da universidade. Dessa maneira, é oportunizado um crescimento do aluno, tendo como consequência, uma melhor preparação para a prática profissional. 
Já o pesquisado B5, descreveu que o mundo do futebol não está nos livros nem na universidade, e sim que ele tem a sua própria realidade.

"Dentro do futebol no caso, existem muitas relações nesse ambiente que só sabe quem esteve dentro dos vestiários, dos espaços de treino, e são coisas que os livros não dizem, onde só se aprende na prática e pela prática”. (B5)

Rodrigues (2003) também segue a linha que o futebol tem suas próprias exigências e vivências quando descreve que no futebol ainda persiste o discurso de que atributos naturais são imprescindíveis para alguém se tornar jogador de futebol, mesmo que esses atributos naturais sejam aperfeiçoados e trabalhados a partir de um conjunto técnicas e conhecimentos inerentes à preparação física, à técnica e à tática.

O futebol é o esporte mais popular do Brasil, com isso, praticamente todos os brasileiros têm contato com o esporte, direta e indiretamente, nas peladas de fim de semana, nos estádios de futebol, pela TV, jornais, rádios e outros meios de comunicação. É a modalidade esportiva mais praticada do mundo, e conquistou grande prestígio no cenário mundial, em boa parte, devido à grande cobertura que o esporte recebe por parte da mídia (RODRIGUES et al., 2016). Dessa forma, a população adquiriu conhecimento, mesmo que às vezes equivocados, sobre o referido esporte.

Sobre a visão do papel de um projeto de extensão na universidade pública, os pesquisados relataram que esse facilita a compreensão da relação teoria e prática fazendo a ligação entre o saber acadêmico e a comunidade, além da concessão de experiência de intervenções na realidade resultando em uma melhor formação.

"O projeto de extensão é importante na medida em que propicia aos estudantes intervenções na realidade prática, fazendo com que estes conheçam a realidade do mercado de trabalho e saiam da universidade com uma boa formação, para que possam atuar da melhor forma possivel na sua profissão". (B1)

"Tem um papel importante para o acadêmico, pois facilita a compreensão e relação de teoria e prática". (B2)

"De fundamental importância, pois lhe concede experiência. Você vai ver que nem tudo é do jeito que está nos livros, vai lhe engrandecer profissionalmente e como pessoa também pelo contato que terá com outras pessoas". (B3)

"Além de uma forma de propiciar a prática pedagógica ao estudante, ela mantém a ligação entre a universidade e a comunidade”. (B4)

"Como uma via de mão dupla onde ganham os estudantes e consequentemente os individuos que estão fora da universidade que estão se beneficiando de tal projeto”. (B5)

As respostas dos participantes assemelham-se a opinião de Jezine (2004), quando esta afirma que a extensão universitária foi repensada em busca da superação da ideologia de prestação de serviços assistencialistas, caminhando para uma relação dialógica entre as universidades e sociedade que oportunize a troca de saberes com ênfase na relação teoria-prática.

Relacionando o conceito central da autora com a opinião dos bolsistas sobre o papel da extensão, a relação dialógica entre universidade e sociedade possibilita a ligação do saber acadêmico aplicado na comunidade através de experiências reais de intervenção. É através dessa contextualização que a instituição tenta diminuir a distância entre teoria e prática fazendo com que os alunos possam entender esses fatores de forma conjunta. 


\section{A Educação Física e o Futebol}

Quando indagados sobre o interesse de continuar desenvolvendo atividades na mesma área que o projeto foi dedicado, todos os pesquisados descreveram que pretendem trabalhar com o futebol, mas em áreas distintas como escola, clube, futsal entre outros.

"Pretendo estudar mais sobre o futebol, estagiar novamente em algum clube de futebol para adquirir mais conhecimentos práticos, para que possa me tornar um profissional capacitado". (B1)

"Trabalhar novamente com a formação de jovens".

"Aonde tiver oportunidade, seja na aula de Educação Física ou na seleção da escola ou quem sabe em um clube se tiver oportunidade, levando como princípio o jogo condicionado". (B3)

"Respondi que sim, mas o futsal chama mais minha atenção que o futebol. Penso muito em trabalhar nessa área com equipes escolares". (B4)

"Talvez tentar o mercado dentro de um clube de futebol, ou projeto social, ou mesmo tentar desenvolver e organizar o esporte em meu município". (B5)

Corroborando a descrição dos participantes, Carravetta (2006) afirma que a complexidade e a diversidade de áreas que englobam o futebol têm ocasionado uma ampliação das especializações como meios imprescindíveis para o desenvolvimento do futebol e do ganho técnico-competitivo dos times.

Apesar de estarem divididos em áreas distintas, todos os participantes pretendem trabalhar no futebol. Um dos motivos para tal separação é a grande abrangência de especialidades e áreas que o futebol engloba, conforme descrito pelo autor anteriormente citado, o que não negligência que estes alunos trabalhem em outra área. A experiência adquirida no projeto traz ganhos para a própria pratica pedagógica necessária para qualquer intervenção didática, além da própria vivência dentro do futebol que não pode ser descartado. Os participantes tiveram experiências dentro do projeto como professor de escolinha de futebol, preparador físico, treinador de equipes competitivas, árbitros de futebol e um dos colaboradores trabalhou como auxiliar de gestor no clube. Consideramos que todas essas experiências, possam contribuir, futuramente, na disputa por um espaço no mercado de trabalho do futebol.

Na perspectiva da ação pedagógica, seja qual for a função no futebol, para Scaglia (1999), uma proposta que vise o ensino do futebol, seja ele de rendimento ou não, não pode tirar a possibilidade de promover o bem-estar dos alunos e deve contribuir para a sua formação humana. Esta proposta deverá estar pautada numa prática pedagógica que desenvolva os valores éticos das regras dos jogos, dos jogadores, da escola, da universidade e do clube.

No que diz respeito às possibilidades de trabalho da EF dentro de um clube de futebol, todos seguiram basicamente a mesma linha de opinião: preparadores, treinador principal, auxiliar, escolinhas, fisiologista, coordenador, cargos administrativos, etc.

"Preparador físico, fisiologista, auxiliar técnico, preparador de goleiros, treinador principal”. (B1)

"Na formação de base, professor de escolinhas, na preparação física, técnico e coordenador". (B2)

"Técnico, auxiliar técnico, fisiologista, preparador físico". 
"Como treinador, se pode atuar desde as escolinhas formativas, passando pela base até o profissional. Podendo atuar também em cargos administrativos como dirigente e outros, caso invista em sua formação". (B4)

"Preparação física, treinamento técnico/tático, diretor, acessória, olheiro, preparador/ treinador de goleiros, são muitas possibilidades de trabalho com o futebol”. (B5)

Para Carraveta (2006), no futebol, pode-se trabalhar várias áreas, além do treinador que é o responsável por coordenar e gerenciar as atividades dos especialistas, existe ainda cerca de 16 profissionais que compõem esse time de especialistas: diretor de futebol; assessor de imprensa; supervisor; roupeiro; técnico principal; preparador físico; auxiliar técnico; cinegrafista; treinador de goleiros; médico; fisioterapeuta; enfermeiro; massagista; fisiologista; nutricionista; psicólogo e assistente social.

Entendemos que para atuar nessa área tão disputada como é o futebol, necessita-se de que o profissional possua qualificação satisfatória para desempenhar suas funções. Ainda mais quando falamos de futebol de alto rendimento, área de grande concorrência e que são exigidos bons resultados constantemente.

A forma que os alunos como futuros profissionais devem obter essa qualificação é primeiramente através de sua formação inicial em que, além das disciplinas obrigatórias, eles podem participar de projetos de extensão voltados para sua área de especificidade. Posteriormente, para complementar os fatores citados acima, existem cursos especializantes que tratam diretamente as temáticas de interesse central e que devem embasar esse profissional para uma melhor intervenção em sua área.

Como já referido, a pesquisa mostrou que persiste um distanciamento entre teoria e prática na formação dos estudantes. Apesar de que uma boa gama de conteúdo do futebol seja contemplada nas disciplinas, estas não oportunizam, efetivamente, a prática desse esporte. Em conformidade com os propósitos deste texto, acreditamos que a experiência proporcionada pelo projeto "A inserção da Universidade no Futebol" possa potencializar e capacitar os futuros profissionais de EF, habilitandoos para atuarem na formação futebolística em estreita articulação teoria-prática, notadamente no que se refere à aplicação dos conhecimentos teóricos, seja em escolinhas de formação ou em equipes competitivas. Em efeito, a realidade vivenciada no projeto de extensão os constituiu - de alguma forma - "diferenciados" em relação a colegas que não tiveram a vivência do futebol na prática.

Nessa perspectiva, entendemos que o profissional que pretende trabalhar com o futebol, deva contribuir com a formação integral - cognitiva, motora, afetiva e social - dos alunos. Este processo depende da atuação efetiva do profissional, diretamente vinculada ao público alvo, considerando a sua formação enquanto indivíduo, conhecedor de seus direitos e deveres, dentro e fora do campo de futebol. Assim, a formação do profissional de EF, para trabalhar com futebol, deve ter objetivos, conteúdos, metodologias e sistema de avaliação bem definidos, na perspectiva da formação de indivíduos autônomos, com capacidade de atender a diversidade de aplicação do conhecimento nas diferentes possibilidades de atuação/trabalho.

Em relação ao tipo de atividades que eles pretendem desenvolver na área de intervenção do futebol, alguns pretendem trabalhar na escolinha, categoria de base, auxiliar técnico, ou treinador.

"Pretendo ser professor de escolinha, auxiliar técnico ou até mesmo treinador principal”. (B1)

"Gostaria bastante de trabalhar como técnico".

"Já pensei em criar uma escolinha em minha cidade, mas com planos para o futsal". (B4) 
"Gosto muito da base, formação de atletas nos aspectos técnicos/táticos, mas tenho o sonho de tentar a carreira de treinador de equipes profissionais". (B5)

Os voluntários almejam ser técnicos ou professores de escolinha, ambas as funções exigem um papel de protagonismo. Carravetta (2006) afirma que uma das funções específicas que cabe ao educador físico dentro do futebol é a de treinador, que coordena a equipe de especialistas do time e intervém quando necessário. A coerência, segurança, ética e autoridade são características indispensáveis a esse profissional e, necessárias para o desenvolvimento do grupo como um todo.

Segundo Santana (2004), o profissional que almeja trabalhar como professor de escolinha deve possuir competência técnica e compromisso político, domínio das dimensões técnicas, humanas e sócio-político, para que possa assumir o compromisso fundamental de atuar no período em que o esporte é introduzido na vida da criança.

Acreditamos que os futuros profissionais que pretendem trabalhar no futebol, seja qual for a área, deveriam levar como referência no seu trabalho os quatro princípios propostos por J. B. Freire (2003, p. 8-9) para ensinar futebol: ensinar futebol a todos; ensinar futebol bem a todos; ensinar mais do que futebol a todos; e ensinar a gostar do esporte.

Consideramos que pretende ensinar/trabalhar no futebol deva proporcionar para seus alunos o desenvolvimento de um acervo de habilidades e conhecimentos diversificados, para que possam aproveitar essas habilidades em muitos outros contextos de vida.

Encara-se que o trabalho dentro do projeto de extensão lhes propiciou uma oportunidade única de obter esse primeiro contato com o seu possível futuro ambiente de trabalho. Oportunizando a chance de vivenciar situações na qual eles pudessem colocar em prática as teorias trabalhadas em sala, assim como ter a oportunidade de vivenciar aquelas situações que não são previstas durantes as disciplinas da universidade. Tudo isso pode ser encarado como ganho em seu desenvolvimento profissional dentro de uma carreira tão competitiva como o meio do futebol, assim contribuindo ativamente na formação destes futuros profissionais.

Reconhecemos a dificuldade de os cursos de EF darem conta de toda a formação e formarem profissionais prontos e acabados, até porque não é este o seu objetivo. Torna-se necessário, também, o reconhecimento de outros espaços de formação para que esses profissionais busquem o aperfeiçoamento constante na sua área de atuação. Acreditamos que os alunos que vivenciaram o projeto de extensão aqui referido, buscaram essa qualificação, para além dos "muros da universidade".

Entendemos que ensinar futebol não é um trabalho fácil. Aquele que se propõe a ensiná-lo precisa ter claro qual é sua proposta de ensino, pois os pais e a sociedade têm o direito de saber o que este profissional propõe ou pretende para a formação de seus filhos. Precisam saber quais os valores que estão sendo desenvolvidos com os alunos, que estão e continuarão vivendo em sociedade, pois não é apenas um estudante ou um atleta de futebol, mas um filho, um irmão, um pai e, provavelmente, um futuro treinador ou outro profissional qualquer.

\section{O projeto a inserção da universidade no futebol}

Quando perguntados sobre o auxílio do projeto de extensão para o seu futuro profissional, os bolsistas responderam que a experiência de atuar profissionalmente e os conhecimentos proporcionados pela prática contaram bastante para o exercício da profissão futuramente.

"Sim, pois consegui conhecimentos e vivências que podem me auxiliar em um futuro profissional dentro do futebol”. (B1)

"Sim, através da experiência em um ambiente muito dificil de entrar, conhecimentos que apenas a prática proporciona e contatos pessoais". (B2) 
"Sim, responsável por tudo que sei, já que foi a primeira vez que pude planejar e intervir em que eu era o responsável pela aula". (B3)

"Sim, me sinto bem mais preparado, pois não enfrentarei mais nenhuma grande novidade". (B4)

"Sim, no futebol, assim como em outros setores e acredito que até mais, as experiências que você tem te validam muito para o mercado. Dessa forma, participando de um projeto como esse pioneiro agrega muito no currículo". (B5)

Damo (2005) corrobora as afirmativas acima, dizendo que apesar do quadro aparentemente desfavorável, ainda que na categoria profissional, os graduados em EF possuem grandes chances de lograrem êxito na profissão.

Percebe-se que há uma ampla gama de áreas onde o profissional de EF pode inserir-se no cotidiano de um clube. Para isso, basta que esse possua a qualificação necessária para atuar nessa área tão disputada que é o esporte de alto rendimento.

Relacionando os dados obtidos através dos colaboradores com o edital do projeto de extensão "A inserção da universidade no futebol", concebe-se a UFC como uma instituição de ensino, pesquisa e extensão que produz de conhecimento. O projeto procurou promover a interação entre comunidade e instituição, almejando cooperar com o trabalho realizado pelas escolinhas e as equipes esportivas do Ferroviário. No qual a universidade auxiliou com a proposta pedagógica e recursos humanos, favorecendo-se da oportunidade da prática pedagógica e da pesquisa para seus alunos.

Dentre os objetivos citados no projeto, alguns valem ser destacados: promover a interação do IEFES/UFC com a sociedade; Desenvolver trabalhos científicos e pesquisas sobre o futebol; Coordenar e desenvolver um projeto de ensino-aprendizagem e treinamento, nas escolinhas de formação do Ferroviário; Participar do planejamento de treinos das equipes de competição sub 15 e sub 17; Oportunizar uma nova vivência esportiva, na perspectiva formativa e competitiva do desporto, para os alunos do IEFES/UFC.

A descrição do B1 sobre o que foi marcante na sua participação no projeto constatou que muito dos objetivos traçados foram alcançados.

"Um ponto marcante foi uma reunião acerca do planejamento, gestão da equipe e de alguns atletas da equipe sub 15, reunião esta que aconteceu com o diretor de futebol, o professor responsável pelo projeto de extensão, o treinador e eu, neste dia pude perceber que é muito importante o profissional está sempre em busca de conhecimento e se capacitar, pois verifiquei que os dois primeiros profissionais tinham uma visão totalmente ampla do fenômeno futebol, enquanto que o treinador por não ser tão capacitado, apresentava poucas ideias que contribuíssem com a equipe, dessa forma percebi que é muito importante haver uma junção entre os aspectos teóricos com os práticos”. (B1)

Outro objetivo importante que projeto se destinava era oportunizar uma nova vivência esportiva, na perspectiva formativa e competitiva do desporto, para os alunos do IEFES/UFC. Pelas respostas dos investigados, este objetivo foi alcançado com êxito. O projeto proporcionou para os alunos o que Damo (2005) constatou que diferencia um ex-atleta de um aluno universitário. Segundo o autor, apesar dos ex-atletas carregarem uma bagagem prática grande e de terem passado por várias ocasiões fundamentais para a prática esportiva (diferentes métodos de treinamento, diferentes tipos de comando, vivenciar o decorrer do jogo em si e suas situações boas e ruins), eles não possuem conhecimentos científicos em áreas como fisiologia, biomecânica, aprendizagem motora, didática, pedagogia. Assim, a experiência adquirida no projeto e o embasamento teórico encontrada nas cadeiras da universidade, podem dar ao aluno participante do projeto, um diferencial na concorrência para o mercado de trabalho no futebol. 
Outro aspecto relevante foi citado por B2, quando relata um fato marcante no projeto, que foi o reconhecimento de outras pessoas sobre o ótimo trabalho que executavam.

\begin{abstract}
"Um dia em que devíamos dar aula e uma turma da universidade iria observar a aula. Tínhamos a aula planejada e organizada, mas no dia começou a aparecer vários imprevistos e problemas, tinha muita chance de dar errado. Conseguimos passar por esses problemas e aplicamos a aula como tínhamos planejado, com algumas pequenas adaptações. No final, um senhor que fazia um serviço no campo falou que aquela era uma aula de verdade, que cumpria a função de ensinar aos alunos e não apenas jogar a bola pra eles. A lição é que, problemas vão ocorrer e devemos estar prontos para corrigir e que se está fazendo um trabalho bom você será reconhecido". (B2)
\end{abstract}

Pela descrição dos alunos, o projeto alcançou o objetivo que um trabalho de extensão se propõe, segundo Melo Neto (2002). Para o autor, além de colocar em mútua correlação o ensino e a pesquisa, a extensão assume um papel filosófico de maneira que busca a superação da dicotomia entre teoria e prática através do encaminhamento das teorias da universidade tratadas no ensino para a prática contextualizada na pesquisa dentro do projeto de extensão.

Através do que foi relatado acima, pode-se constatar por meio de fatos concretos que, além de inseridos dentro de um clube de futebol profissional, estes alunos tiveram a oportunidade única de uma nova vivência esportiva e prática pedagógica no contexto futebolístico. Prática esta que gerou um conhecimento e desenvolvimento profissional extremamente singular relatado pelos próprios participantes, além da grande oportunidade de realizar pesquisas e estudos dentro desse contexto.

\title{
CONSIDERAÇÕES FINAIS
}

Com a finalidade de alcançar os objetivos que nortearam o estudo, buscou-se foi verificar a percepção dos bolsistas sobre o projeto de extensão "A inserção da Universidade no Futebol" em relação à dimensão teoria e prática na formação em Educação Física.

Tomando como base a análise e discussão dos dados juntamente com o referencial teórico da pesquisa, serão destacados neste capítulo alguns pontos que vão ao encontro dos objetivos do trabalho proposto.

Em relação à percepção dos bolsistas sobre a relação teoria e prática na sua formação, os pesquisados entendem que há um distanciamento entre as duas temáticas. No qual, em suas falas, a teoria está desvinculada da prática num discurso de independência, sugerindo a ideia de que existe uma relação não confluente na qual um fator assumiria um discurso conceitual enquanto o outro seria a experiência em si.

Percebe-se que isso é reflexo da formação que esses futuros profissionais recebem, de modo que, quando perguntados sobre a relação teoria e prática dentro do contexto da formação, os participantes relataram que alguns dos próprios discentes da instituição não conseguem fazer uma correlação entre os dois fatores. Isso pode acarretar um afastamento pelo fato de, desde o início de sua formação, esses alunos encararem como uma relação problemática o que deveria ser vista como correlacional.

Dessa forma, seria necessária uma revisão dos currículos vigentes, de modo que estes ocasionassem uma mudança de panorama na atuação pedagógica dos futuros professores. Mudança esta que proporcionasse um vínculo entre teoria e prática, fazendo com que o aluno compreenda clara e objetivamente o que está sendo proposto e aplique no seu futuro profissional.

No que diz respeito à relevância atribuída pelos bolsistas ao projeto de extensão para sua formação, os colaboradores relataram que a extensão universitária é um trabalho entre o meio acadêmico e a sociedade, que possibilita o contato com a realidade externa à instituição.

A ideia de extensão dos participantes revelou a importância que ela possui para a formação, pois através desta há a possibilidade do ensino e da pesquisa de forma contextualizada. Fato ratificado 
pelo próprio questionário dos alunos quando estes citam que a extensão lhes proporcionou o conhecimento da realidade profissional e da aplicação de teoria na realidade prática.

Levando-nos a um ponto importante que seria, a partir desse conhecimento da realidade externa à instituição de ensino, os alunos encaminharem as teorias trabalhadas na universidade para a prática contextualizada inserida no projeto, dessa forma minimizando a dicotomia tratada nesta investigação. Foi constatado, através desta pesquisa, que a extensão contribuiu para o desenvolvimento acadêmico dos participantes, devido às experiências vivenciadas que os possibilitaram um melhor conhecimento da realidade e preparação para a prática pedagógica.

Quanto à opinião dos participantes sobre o futuro profissional dentro do contexto futebolístico, todos afirmaram pretender seguir uma carreira que envolva o futebol ou futsal, seja em clubes ou escolas. Eles, em sua maioria, declararam que almejam trabalhar como técnicos ou professores de escolinha. Que, apesar de profissões distintas, apresentam grandes semelhanças.

No que concerne à contribuição desse projeto de extensão para seu futuro profissional, os pesquisados, por estarem inseridos em um clube de futebol profissional, receberam a oportunidade ímpar de uma vivência esportiva singular com a chance desenvolver sua prática pedagógica num contexto real de ensino, ocasião que poucos têm privilégio. Nesse caso, o papel da extensão foi proporcionar uma vivência na formação inicial desses futuros profissionais. Formação que deve ser complementada com cursos específicos para que, dessa maneira, eles possam desempenhar suas funções com excelência.

Com tudo que foi citado ao decorrer da discussão desta pesquisa e, considerando ainda o referencial teórico e o questionário aberto com os bolsistas participantes do projeto de extensão, acreditamos ter alcançado os objetivos traçados ao início da investigação. No qual pude verificar a importância atribuída pelos participantes ao seu referido projeto de extensão e sua relação com teoria e prática para sua formação profissional. E, após todo o processo de pesquisa, pode-se afirmar que esta proporcionou um desenvolvimento profissional e pessoal do pesquisador, pois novos conhecimentos foram conhecidos e compartilhados.

Muitas são as possibilidades de continuidade para pesquisa, como sugestões apresento as seguintes propostas:

- Investigar outros projetos de extensão dentro do IEFES/UFC;

- Comparar projetos de extensão de outros cursos com os projetos da EF;

- Investigar alunos que estão inseridos no mercado de trabalho e participaram de projetos de extensão na UFC.

\section{REFERENCIAS}

BARDIN L. Análise de conteúdo. Lisboa: Edições 70, 2002.

CARRAVETA, E. S. Modernização da Gestão do Futebol Brasileiro: perspectivas para a qualificação do rendimento competitivo. Porto Alegre: AGE, 2006.

CERVO, A. L; BERVIAN, P. A. Metodologia científica. São Caetano do Sul: Gráficos Burti, 1998.

DAMO, A. Do dom a profissão: uma etnografia do futebol de espetáculo a partir da formação de jogadores no Brasil e na França. 2005. Tese (Doutorado em Antropologia Social) - Universidade Federal do Rio Grande do Sul, Porto Alegre, 2005.

DARIDO, S. C. Teoria, prática e reflexão na formação profissional em Educação Física. Motriz, v. 1, n. 2, p. 124-128, 1995.

FREIRE, J. B. Pedagogia do futebol. Campinas, SP: Autores Associados, 2003. 
GUNTHER, M. C. C.; MOLINA NETO, V. Formação permanente de professores de educação física na rede municipal de ensino de Porto Alegre: uma abordagem etnográfica. Revista Paulista de Educação Física, v. 14, n. 1, p. 85-91, 2000.

JEZINE, E. As práticas curriculares e a extensão universitária. In: Anais do $2^{\circ}$ Congresso Brasileiro de Extensão Universitária. Universidade Federal de Minas Gerais: Belo Horizonte, 2004.

MARCELLINO, N. C. “A Dicotomia Teoria/Prática na Educação Física”. ANAIS III Semana da Educação Física - Universidade São Judas Tadeu: São Paulo, p. 31-37, 1995.

MELO NETO, J. F. Extensão Universitária: bases ontológicas. João Pessoa: Editora Universitária, 2002.

NEGRINE, A. Instrumentos de coleta de informações na pesquisa qualitativa. A planificação, programação, e periodização do treino em futebol. EFDeportes.com, Revista Digital, n. 89, 2005.

RODRIGUES, F. X. F. A formação do jogador de futebol no Sport Club Internacional. 2003. 200f. Dissertação (Mestrado em Sociologia) - Universidade Federal do Rio Grande do Sul, Porto Alegre, 2003.

RODRIGUES, W. C. Metodologia Científica. São Paulo: FATEC/IST Paracambi, 2007.

RODRIGUES, A. L. P. et al. A formação de jovens atletas nas escolinhas de futebol em Fortaleza CE. Revista Brasileira de Futsal e Futebol, v. 8, n. 31, p. 340-347, 2016.

SANTANA, W. C. Futsal: apontamentos pedagógicos na iniciação e na especialização. Campinas, SP: Autores Associados, 2004.

SCAGLIA, A. J. O futebol que se aprende e o futebol que se ensina. 1999. 242f. Dissertação (Mestrado em Educação Física) - Universidade Estadual de Campinas, Campinas, 1999.

STRELHOW, B. S. Pedagogia da Tolerância. Revista Eletrônica do Núcleo de Estudos e Pesquisa do Protestantismo (NEPP) da Escola Superior de Teologia, v. 12, 2007.

TOJAL, J. B. G. “A dicotomia Teoria/Prática na Educação Física” ANAIS III Semana de Educação Física. Universidade São Judas Tadeu: São Paulo, p. 17-21, 1995. 